\title{
Redefining the impact of oxygen and hyperventilation after the Norwood procedure
}

Scott M. Bradley, MD

Andrew M. Atz, MD ${ }^{\mathrm{b}}$

Janet M. Simsic, MD

From the Divisions of Cardiothoracic Surgery $^{\mathrm{a}}$ and Pediatric Cardiology, ${ }^{\mathrm{b}}$ Medical University of South Carolina, Charleston, SC.

Read at the Eighty-third Annual Meeting of The American Association for Thoracic Surgery, Boston, Mass, May 4-7, 2003.

Received for publication May 2, 2003; revisions requested Sept 11, 2003; accepted for publication Sept 29, 2003.

Address for reprints: Scott M. Bradley, MD, Division of Cardiothoracic Surgery, Medical University of South Carolina, 96 Jonathan Lucas Street, Charleston, SC 29425 (E-mail: bradlesm@musc.edu).

J Thorac Cardiovasc Surg 2004;127:473-80

$0022-5223 / \$ 30.00$

Copyright (@) 2004 by The American Association for Thoracic Surgery

doi:10.1016/j.jtcvs.2003.09.028
Objective: Postoperative management after the Norwood procedure is aimed at optimizing systemic oxygen delivery and mixed venous oxygen saturation. High levels of fraction of inspired oxygen and hyperventilation may increase pulmonary blood flow at the expense of systemic flow. This study determines the effects of these interventions on mixed venous saturation and systemic oxygen delivery in postoperative neonates.

Methods: We prospectively studied the effects of $100 \%$ fraction of inspired oxygen and hyperventilation in 14 neonates (median age 8 days) 1 to 3 days after the Norwood procedure, while they were sedated, paralyzed, and mechanically ventilated. After establishment of baseline conditions (fraction of inspired oxygen $=29 \%$ $\pm 2 \%$, normal ventilation), patients were exposed to each of the 2 interventions in random order. Mixed venous saturation was measured through a transthoracic line in the superior vena cava. Oxygen excess factor $(\Omega=$ systemic oxygen delivery/ oxygen consumption) was used as an indicator of systemic oxygen delivery.

Results: High levels of fraction of inspired oxygen produced significant increases from baseline in systemic saturation $(90 \% \pm 1 \%$ vs $80 \% \pm 1 \%, P<.01)$, mixed venous saturation $(54 \% \pm 3 \%$ vs $44 \% \pm 2 \%, P<.01)$, and oxygen excess factor $(2.6 \% \pm 0.2 \%$ vs $2.3 \pm 0.2 \%, P<.01)$, but there was no change in arteriovenous saturation difference or blood pressure. Hyperventilation resulted in no changes in systemic or mixed venous saturation, arteriovenous saturation difference, oxygen excess factor, or blood pressure.

Conclusions: High levels of fraction of inspired oxygen can improve mixed venous oxygen saturation and systemic oxygen delivery after the Norwood procedure. Hyperventilation does not change either mixed venous saturation or oxygen delivery. Management protocols aimed at minimizing the fraction of inspired oxygen and carefully controlling ventilation may not be warranted.

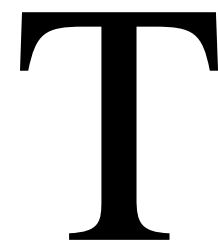

he Norwood procedure is widely used to palliate neonates with hypoplastic left heart syndrome and other heart defects with a functional single ventricle and systemic outflow tract obstruction. Operative deaths may occur in the early postoperative period in the setting of low systemic cardiac output and oxygen delivery. ${ }^{1-3}$ Efforts to avoid such deaths have focused in part on limiting pulmonary blood flow and improving systemic perfusion. Computer models of single ventricle circulation have indicated that systemic oxygen delivery is maximized at a pulmonary-to-systemic flow ratio (Qp:Qs) of approximately $1.0 .^{4-6}$ Mixed venous oxygen saturation mirrors tissue oxygen levels and peaks at a Qp:Qs near 1.0. Thus, postoperative management after the Norwood procedure is aimed at optimizing systemic oxygen delivery and mixed venous oxygen saturation.

Ventilatory interventions are important methods of manipulating Qp:Qs in patients with parallel pulmonary and systemic circulations. ${ }^{7-12} \mathrm{~A}$ high level of fraction 
of inspired oxygen $\left(\mathrm{FIO}_{2}\right)$ and hyperventilation are 2 interventions that may potentially increase pulmonary blood flow, possibly at the expense of decreased systemic blood flow, systemic oxygen delivery, and mixed venous oxygen saturation. However, little information is available on the effects of these interventions in postoperative neonates. This study determines the effects of high $\mathrm{FIO}_{2}$ and hyperventilation on mixed venous oxygen saturation and systemic oxygen delivery in neonates after the Norwood procedure.

\section{Methods}

\section{Patient Demographics}

This study was approved by the Institutional Review Board of the Medical University of South Carolina, and informed consent was obtained from all patients. Fourteen patients undergoing the Norwood procedure were prospectively enrolled. Their median age was 8 days (range 4-31 days), and their median weight was $3.0 \mathrm{~kg}$ (range 2.0-4.2 kg). There were 9 boys and 5 girls. Diagnoses included hypoplastic left heart syndrome (11 patients), doubleinlet left ventricle (2 patients), and tricuspid atresia with transposition (1 patient). Operations consisted of a standard or modified Norwood procedure with pulmonary homograft reconstruction of the neoaorta in all patients. All operations included a modified Blalock-Taussig shunt (size $3.5 \mathrm{~mm}$ in 8 patients and $4.0 \mathrm{~mm}$ in 6 patients). Regional low-flow perfusion of the innominate artery through the shunt was used in the last 8 of the 14 patients. The mean operative support time (cardiopulmonary bypass + circulatory arrest) was $187 \pm 34$ minutes, and the mean myocardial ischemic time was $40 \pm 10$ minutes. The mean circulatory arrest time was $42 \pm 12$ minutes in the first 6 patients and $5 \pm 1$ minute in the 8 patients with regional low-flow perfusion. Hospital survival for the study patients was $93 \%$.

Patients were studied in the intensive care unit, while hemodynamically stable, at a median of 2 days (range 1-3 days) after the Norwood procedure. The sternum was open in 8 patients and closed in 6 patients. During the study, patients were sedated (fentanyl at $20 \mu \mathrm{g} \cdot \mathrm{kg} \cdot \mathrm{h}$ or morphine sulfate at $0.1 \mathrm{mg} \cdot \mathrm{kg} \cdot \mathrm{h}$ infusion), paralyzed (vecuronium $0.1 \mathrm{mg} / \mathrm{kg}$ ), and mechanically ventilated. No patient had spontaneous ventilation during the study. All patients received dopamine at 3 to $12 \mu \mathrm{g} \cdot \mathrm{kg} \cdot \mathrm{min}$. In addition, 12 patients also received milrinone at 0.3 to $0.7 \mu \mathrm{g} \cdot \mathrm{kg}$ - min, and 3 patients received epinephrine at 0.02 to $0.06 \mu \mathrm{g} \cdot \mathrm{kg}$ - min. All infusions were maintained at constant rates, and no other medical interventions were undertaken during the study. Mean hematocrit was $42 \% \pm 3 \%$ (range $37 \%-48 \%$ ). All patients were in sinus rhythm and maintained at normothermia $\left(37^{\circ} \mathrm{C}\right)$ throughout the study. Patients were mechanically ventilated with a Servo 300 ventilator (Siemens-Elema AB, Solna, Sweden) in pressure-regulated volume control mode (6 patients) or synchronized intermittent mandatory ventilation mode ( 8 patients). During the study, tidal volume was 14 to $28 \mathrm{~mL} / \mathrm{kg}$, inspiratory time was 0.65 to 0.8 seconds, and positive end-expiratory pressure was 2 to $4 \mathrm{~cm} \mathrm{H}_{2} \mathrm{O}$; none of these settings were altered during the study. Baseline $\mathrm{FIO}_{2}$ was adjusted to give a systemic oxygen saturation of $75 \%$ to $80 \%$ and ranged from 0.21 to 0.5 . Baseline ventilator rate was adjusted to give a normal $\mathrm{pH}$ and partial pressure of carbon dioxide $\left(\mathrm{PCO}_{2}\right)$.

\section{Study Protocol}

After establishment of baseline conditions, each patient was exposed to the 2 interventions (high $\mathrm{FIO}_{2}$ and hyperventilation) in random order. High $\mathrm{FIO}_{2}$ was achieved by increasing the $\mathrm{FIO}_{2}$ to 1.0, and hyperventilation was achieved by increasing the ventilator rate. Each intervention was followed by a return to baseline conditions, so that each patient was studied at 5 consecutive time points: (1) baseline, (2) intervention 1, (3) baseline, (4) intervention 2, and (5) baseline. At least 15 minutes were allowed for stabilization at each time point before measurements were made.

Arterial blood gases and arterial pressure were determined from umbilical or femoral arterial catheters. Systemic oxygen saturation $\left(\mathrm{SaO}_{2}\right)$ was measured by extremity pulse oximetry (Hewlett-Packard, Palo Alto, Calif) verified by co-oximetry. Common atrial pressure was measured through transthoracic lines placed in the operating room. Mixed venous oxygen saturation $\left(\mathrm{SvO}_{2}\right)$ was determined by co-oximetry from samples drawn from transthoracic lines in the superior vena cava. These lines were placed through the right atrial free wall into the superior vena cava, and position was verified by postoperative chest radiograph. The following calculations were made: arteriovenous oxygen saturation $\left(\mathrm{AVO}_{2}\right)$ difference $=\left(\mathrm{SaO}_{2}-\mathrm{SvO}_{2}\right)$; oxygen excess factor $(\Omega)^{5,13-15}=$ systemic oxygen delivery/systemic oxygen consumption $=\mathrm{CaO}_{2}$ $\times \mathrm{Qs} /\left(\mathrm{CaO}_{2}-\mathrm{CvO}_{2}\right) \times \mathrm{Qs}=\mathrm{SaO}_{2} /\left(\mathrm{SaO}_{2}-\mathrm{SvO}_{2}\right)$, where $\mathrm{CaO}_{2}=$ oxygen content of systemic arterial blood, $\mathrm{CvO}_{2}=$ oxygen content of systemic venous blood, and $\mathrm{Qs}=$ systemic blood flow. If oxygen consumption remains constant, then $\Omega$ is directly proportional to systemic oxygen delivery. ${ }^{5,13-15}$ The quantity of dissolved oxygen $\left(\mathrm{PO}_{2} \times 0.003\right)$ was negligible and omitted from the calculation of $\Omega$. Pulmonary venous saturation was not measured in our patients. Calculations of Qp:Qs were therefore deliberately avoided because of the realization that small errors in assumed pulmonary venous saturation result in relatively large errors in the calculated Qp:Qs. ${ }^{5}$

\section{Statistics}

Results are shown as mean \pm SEM. All data were normally distributed (Shapiro-Wilk W test) with the exception of systolic blood pressure and mean airway pressure. Measured variables during each intervention were compared with the average of the preintervention and postintervention baselines by paired $t$ test or Wilcoxon signed rank test, as appropriate. There was no significant effect of the order of treatment on the changes produced by the 2 interventions.

\section{Results \\ High $\mathrm{FiO}_{2}$}

High $\mathrm{FIO}_{2}$ was achieved by increasing the $\mathrm{FIO}_{2}$ from baseline values to 1.0 , with no change in ventilator rate or tidal volume (Table 1). This intervention produced an increase in mean arterial $\mathrm{Po}_{2}$ from 40 to 56 torr, but no clinically important changes in arterial $\mathrm{PCO}_{2}, \mathrm{pH}$, or bicarbonate level (Table 2). High $\mathrm{FIO}_{2}$ produced significant increases from baseline values in both $\mathrm{SaO}_{2}(11 \% \pm 1 \%, P<.01)$ and $\mathrm{SvO}_{2}$ $(11 \% \pm 1 \%, P<.01)$ (Table 3, Figure 1). During high $\mathrm{FIO}_{2}$, $\mathrm{SvO}_{2}$ increased in each of the 14 patients, with the increase ranging from $4 \%$ to $17 \%$. High $\mathrm{FIO}_{2}$ produced no change in 
TABLE 1. Ventilator parameters

\begin{tabular}{|c|c|c|c|c|c|c|}
\hline \multirow[b]{2}{*}{ Parameter } & \multicolumn{3}{|c|}{ High $\mathrm{FiO}_{2}$} & \multicolumn{3}{|c|}{ Hyperventilation } \\
\hline & Baseline & High $\mathrm{F}_{10}$ & $\boldsymbol{P}$ & Baseline & Hyperventilation & $\boldsymbol{P}$ \\
\hline $\mathrm{FlO}_{2}$ & $0.29 \pm 0.02$ & $1.0 \pm 0$ & $<.01$ & $0.29 \pm 0.01$ & $0.29 \pm 0.01$ & 1.0 \\
\hline Rate (breaths/min) & $14 \pm 1$ & $14 \pm 1$ & .3 & $15 \pm 1$ & $30 \pm 1$ & $<.01$ \\
\hline Tidal volume $(\mathrm{mL})$ & $58 \pm 2$ & $58 \pm 2$ & 1.0 & $58 \pm 2$ & $58 \pm 2$ & 1.0 \\
\hline \multicolumn{7}{|c|}{ Airway pressure $\left(\mathrm{cm} \mathrm{H}_{2} \mathrm{O}\right)$} \\
\hline $\begin{array}{l}\text { Peak } \\
\text { Mean }\end{array}$ & $\begin{array}{l}24 \pm 1 \\
5.4 \pm 0.2\end{array}$ & $\begin{array}{c}24 \pm 1 \\
5.5 \pm 0.2\end{array}$ & $\begin{array}{l}.1 \\
.6\end{array}$ & $\begin{array}{l}24 \pm 1 \\
5.6 \pm 0.2\end{array}$ & $\begin{array}{l}23 \pm 1 \\
7.9 \pm 0.4\end{array}$ & $\begin{array}{r}.03 \\
<.01\end{array}$ \\
\hline
\end{tabular}

Values are mean \pm SEM.

$\mathrm{F}_{2}{ }_{2}$, Fraction of inspired oxygen.

TABLE 2. Arterial blood gas values

\begin{tabular}{|c|c|c|c|c|c|c|}
\hline \multirow[b]{2}{*}{ Parameter } & \multicolumn{3}{|c|}{ High $\mathrm{FiO}_{2}$} & \multicolumn{3}{|c|}{ Hyperventilation } \\
\hline & Baseline & High $\mathrm{FiO}_{2}$ & $\boldsymbol{P}$ & Baseline & Hyperventilation & $\boldsymbol{P}$ \\
\hline $\mathrm{Po}_{2}$ (torr) & $40 \pm 1$ & $56 \pm 2$ & $<.01$ & $40 \pm 1$ & $35 \pm 1$ & $<.01$ \\
\hline $\mathrm{PCO}_{2}$ (torr) & $44 \pm 1$ & $47 \pm 2$ & .2 & $42 \pm 1$ & $31 \pm 1$ & $<.01$ \\
\hline $\mathrm{pH}$ & $7.43 \pm 0.01$ & $7.42 \pm 0.01$ & .02 & $7.45 \pm 0.01$ & $7.56 \pm 0.01$ & $<.01$ \\
\hline Bicarbonate (mmol/L) & $28 \pm 1$ & $28 \pm 1$ & .3 & $28 \pm 1$ & $27 \pm 1$ & $<.01$ \\
\hline
\end{tabular}

Values are mean \pm SEM.

$\mathrm{PO}_{2}$, Partial pressure of oxygen; $\mathrm{PCO}_{2}$, partial pressure of carbon dioxide.

TABLE 3. Oxygen saturation data

\begin{tabular}{|c|c|c|c|c|c|c|}
\hline \multirow[b]{2}{*}{ Variable } & \multicolumn{3}{|c|}{ High $\mathrm{FiO}_{2}$} & \multicolumn{3}{|c|}{ Hyperventilation } \\
\hline & Baseline & High $\mathrm{FiO}_{2}$ & $P$ & Baseline & Hyperventilation & $\boldsymbol{P}$ \\
\hline $\mathrm{SaO}_{2}(\%)$ & $80 \pm 1$ & $90 \pm 1$ & $<.01$ & $80 \pm 1$ & $80 \pm 1$ & .8 \\
\hline $\mathrm{SvO}_{2}(\%)$ & $44 \pm 2$ & $54 \pm 3$ & $<.01$ & $42 \pm 3$ & $42 \pm 3$ & .9 \\
\hline $\mathrm{AVO}_{2}$ difference $(\%)$ & $36 \pm 2$ & $36 \pm 2$ & .7 & $38 \pm 2$ & $38 \pm 2$ & .9 \\
\hline Oxygen excess factor & $2.3 \pm 0.2$ & $2.6 \pm 0.2$ & $<.01$ & $2.3 \pm 0.2$ & $2.2 \pm 0.1$ & .5 \\
\hline
\end{tabular}

Values are mean \pm SEM.

$\mathrm{SaO}_{2}$, Systemic oxygen saturation; $\mathrm{SvO}_{2}$, mixed venous oxygen saturation; $\mathrm{AVO}_{2}$, anteriovenous oxygen difference.

$\mathrm{AVO}_{2}$ difference $(0.4 \% \pm 1.1 \%, P=.7)$. However, oxygen excess factor, reflecting systemic oxygen delivery, increased significantly during high $\mathrm{FIO}_{2}$ compared with baseline (Table 3, Figure 1). Blood pressure and common atrial pressure did not change during high $\mathrm{FIO}_{2}$ (Table 4).

There was no apparent influence of either ventricular morphology or an open sternum on the effects of high $\mathrm{FiO}_{2}$. Specifically, there was no difference in the changes during high $\mathrm{FIO}_{2}$ in the 3 patients with a single left ventricle compared with the 11 patients with hypoplastic left heart syndrome. Similarly, there was no difference in the changes seen in the 8 patients with an open sternum compared with the 6 patients with a closed sternum.

\section{Hyperventilation}

Hyperventilation was achieved by increasing the ventilator rate from a mean of 15 to 30 breaths/min while keeping the tidal volume constant (Table 1). This increase resulted in an increase in mean airway pressure (Table 1). Hyperventilation also produced respiratory alkalosis, with a decrease in mean $\mathrm{PCO}_{2}$ from 42 to 31 torr and an increase in mean $\mathrm{pH}$ from 7.45 to 7.56 (Table 2). During hyperventilation, arterial $\mathrm{Po}_{2}$ decreased from 40 to 35 torr (Table 2). However, hyperventilation produced no changes in $\mathrm{SaO}_{2}, \mathrm{SvO}_{2}, \mathrm{AVO}_{2}$, or oxygen excess factor (Table 3, Figure 2). Blood pressure remained unchanged during hyperventilation, whereas there was a small, but significant, increase in heart rate and decrease in common atrial pressure (Table 4).

\section{Discussion}

This study shows that a high level of $\mathrm{FIO}_{2}$ can improve mixed venous oxygen saturation and systemic oxygen delivery in neonates after the Norwood procedure. In contrast, hyperventilation does not alter either mixed venous satura- 

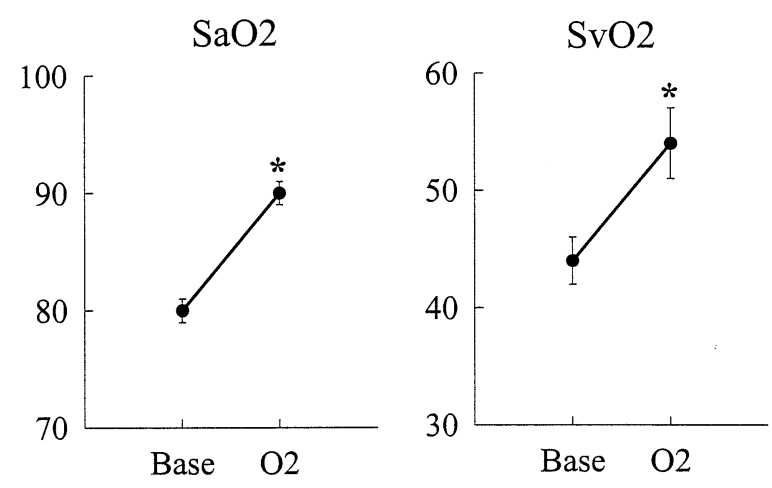

AVO2 difference
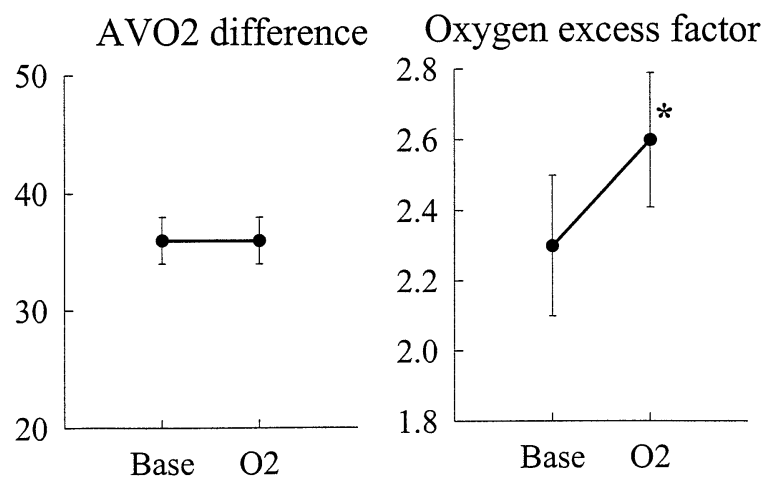

Figure 1. Effect of high $\mathrm{FiO}_{2}$ on oxygen saturations after the Norwood procedure. Values are mean \pm SEM $\left({ }^{*} P<.01\right.$ vs baseline).

tion or oxygen delivery. Neither high $\mathrm{FIO}_{2}$ nor hyperventilation results in deleterious changes in hemodynamic parameters, including blood pressure, heart rate, and common atrial pressure. These findings may have implications for postoperative management strategies.

The results of the Norwood operation have improved considerably during the last decade, partly because of the improvement in postoperative care ${ }^{16}$ Operative deaths may occur in the early postoperative period in the setting of low systemic cardiac output and oxygen delivery. ${ }^{1-3}$ Efforts to avoid such deaths have focused in part on limiting pulmonary blood flow and improving systemic perfusion. Ventilatory interventions have been emphasized as important methods of manipulating pulmonary vascular resistance ${ }^{17}$ and Qp:Qs. ${ }^{7-12}$ Interventions that may increase pulmonary blood flow at the expense of systemic flow include a high level of $\mathrm{FIO}_{2}$ and hyperventilation. These considerations may lead to management strategies that are aimed at avoiding reductions in pulmonary vascular resistance by minimizing inspired oxygen and carefully controlling ventilation. Although ventilatory manipulations have been studied in several animal models of single ventricle circulation, ${ }^{18,19}$ there has been limited study of these strategies in patients.
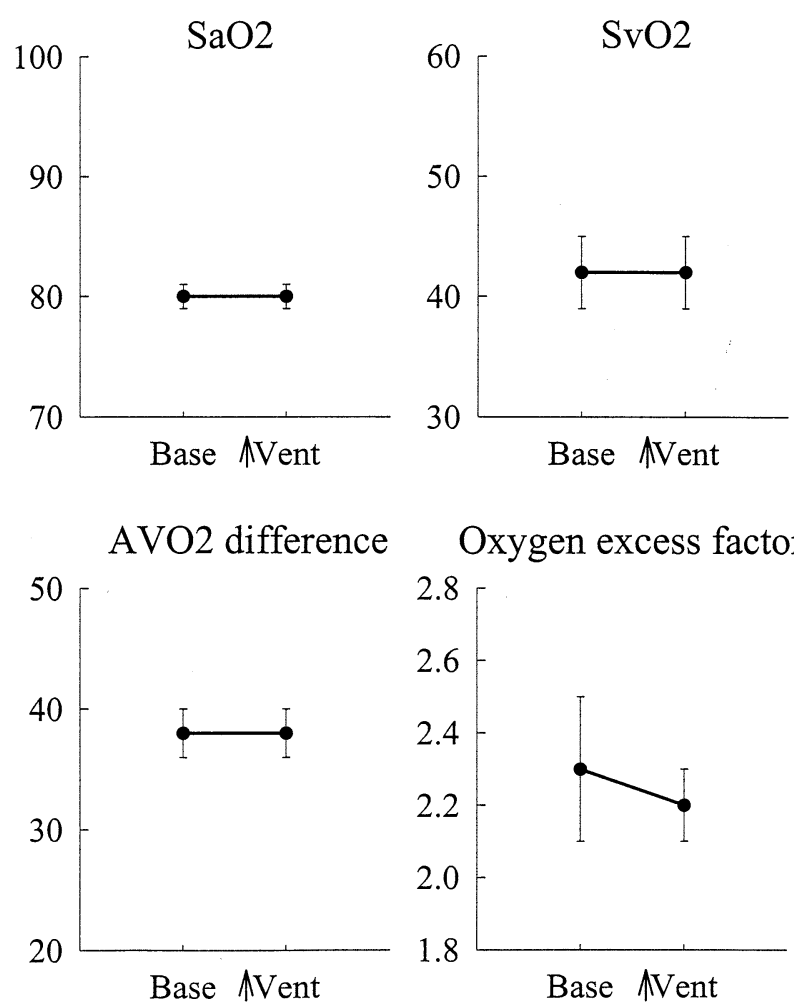

Oxygen excess factor

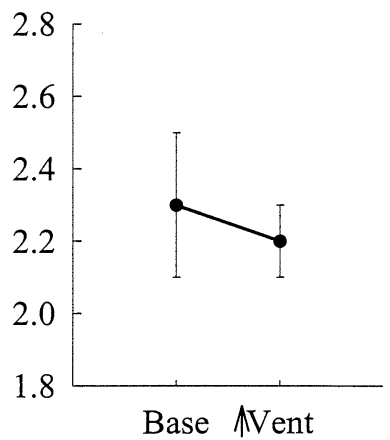

Figure 2. Effect of hyperventilation on oxygen saturations after the Norwood procedure. Values are mean \pm SEM.

Recent research and clinical experience have illustrated the importance of monitoring mixed venous saturation, in addition to systemic oxygen saturation, in patients after the Norwood procedure. Computer models of single ventricle circulation show that systemic oxygen delivery is maximized at a Qp:Qs of 1.0 or less. ${ }^{4-6}$ In these models, systemic oxygen saturation by itself is an inaccurate indicator of Qp:Qs, particularly at levels greater than $75 \%$. Mixed venous saturation provides a more accurate measure of Qp:Qs and oxygen delivery. ${ }^{4-6}$ Monitoring mixed venous saturation in patients after the Norwood operation was first reported by Rossi and colleagues in $1994^{1}$ In a recent experience comprising 115 patients who underwent operations from 1992 to 2001, venous saturation monitoring was the only significant multivariable predictor of improved hospital survival. ${ }^{16} \mathrm{We}$, as well as others, have adopted postoperative mixed venous saturation monitoring after the Norwood procedure. ${ }^{11,14,16,20,21}$ Management is aimed at optimizing mixed venous saturation and oxygen delivery rather than achieving a particular value of systemic saturation. This study was undertaken with these management goals in mind.

In the current study, high $\mathrm{FIO}_{2}$ increased mixed venous saturation but not arteriovenous saturation difference. By the Fick principle, arteriovenous saturation difference is 
TABLE 4. Hemodynamic variables

\begin{tabular}{|c|c|c|c|c|c|c|}
\hline \multirow[b]{2}{*}{ Variable } & \multicolumn{3}{|c|}{ High $\mathrm{FiO}_{2}$} & \multicolumn{3}{|c|}{ Hyperventilation } \\
\hline & Baseline & $\mathrm{High} \mathrm{FiO}_{2}$ & $\boldsymbol{P}$ & Baseline & Hyperventilation & $\boldsymbol{P}$ \\
\hline $\begin{array}{l}\text { Heart rate (beats/min) } \\
\text { Blood pressure }(\mathrm{mm} \mathrm{Hg})\end{array}$ & $161 \pm 4$ & $159 \pm 4$ & .02 & $160 \pm 4$ & $165 \pm 4$ & $<.01$ \\
\hline Mean & $52 \pm 1$ & $52 \pm 2$ & .7 & $51 \pm 1$ & $50 \pm 1$ & .3 \\
\hline Systolic & $75 \pm 2$ & $77 \pm 3$ & .4 & $74 \pm 2$ & $72 \pm 2$ & .2 \\
\hline Diastolic & $36 \pm 1$ & $37 \pm 1$ & .8 & $36 \pm 1$ & $35 \pm 1$ & .2 \\
\hline Common atrial pressure $(\mathrm{mm} \mathrm{Hg})$ & $6.8 \pm 0.4$ & $6.8 \pm 0.4$ & 1.0 & $6.9 \pm 0.4$ & $6.1 \pm 0.4$ & .01 \\
\hline
\end{tabular}

Values are mean \pm SEM.

equal to the ratio of oxygen consumption to systemic blood flow. Under the conditions of sedation and paralysis in this study, it is unlikely that oxygen consumption changed significantly, indicating that systemic blood flow was also unchanged during high $\mathrm{FIO}_{2}$. This is supported by the lack of important changes in heart rate, blood pressure, and common atrial pressure during high $\mathrm{FIO}_{2}$. Thus, the increase in mixed venous saturation seemed to be the result of an increase in systemic saturation in the setting of preserved systemic blood flow.

High $\mathrm{FIO}_{2}$ may have increased systemic saturation by increasing either pulmonary venous saturation or pulmonary blood flow. After the Norwood procedure, pulmonary venous saturation is not generally measured and is often assumed to be normal ( $>96 \%)$. However, a recent study of 12 patients within 3 days of the Norwood procedure found that pulmonary venous desaturation occurred frequently. ${ }^{21}$ Pulmonary venous saturations less than $95 \%$ were observed in 11 of 12 patients, in the absence of radiographic evidence of pulmonary disease, and could occur with an $\mathrm{FIO}_{2}$ greater than $30 \%$. On the basis of this information, it is likely that many of our study patients had pulmonary venous desaturation at baseline, when their mean $\mathrm{FIO}_{2}$ was 0.29. High $\mathrm{FIO}_{2}$ may then have increased systemic oxygen saturation because of an increase in pulmonary venous saturation.

High $\mathrm{FiO}_{2}$ may have also increased systemic saturation by increasing pulmonary blood flow. Oxygen is a known pulmonary vasodilator and could have increased pulmonary flow by decreasing pulmonary vascular resistance. Any increase in pulmonary flow seems to have been accompanied by an increase in overall cardiac output so that "pulmonary overcirculation" with decreased systemic flow, blood pressure, and oxygen delivery did not result. To the extent that total cardiac output increases during high $\mathrm{FIO}_{2}$, this would constitute a volume load on the single ventricle. However, we speculate that any increase in pulmonary flow caused by increasing $\mathrm{FiO}_{2}$ was limited by the fixed resistance of the modified Blalock-Taussig shunt.

In this study, the oxygen excess factor was used as an indicator of systemic oxygen delivery. Oxygen excess factor is defined as the ratio of systemic oxygen delivery to oxygen consumption and is calculated as $\mathrm{SaO}_{2} / \mathrm{SaO}_{2}-$ $\mathrm{SvO}_{2}{ }^{5,13,14}$ If oxygen consumption remains constant, the oxygen excess factor is directly proportional to systemic oxygen delivery. ${ }^{5}$ The oxygen excess factor has been used as a measure of oxygen delivery in a previous computer model of single ventricle circulation ${ }^{5}$ and studies of patients before and after the Norwood procedure. ${ }^{14,15}$ Under the conditions of sedation and paralysis in this study, it is likely that oxygen consumption changed little and that oxygen excess factor provided a reasonable index of systemic oxygen delivery. More direct methods of measuring oxygen delivery in postoperative patients would clearly be valuable.

Under the conditions of this study, hyperventilation had no significant effect, either positive or negative, on oxygen saturations or hemodynamic values. The decrease in arterial $\mathrm{Po}_{2}$, despite no change in systemic oxygen saturation (Table 2), was likely because of the leftward shift in the oxyhemoglobin dissociation curve that results from decreasing $\mathrm{PCO}_{2}$ and increasing $\mathrm{pH}$. Alkalosis has been shown to decrease pulmonary vascular resistance in both children and adults after cardiopulmonary bypass. ${ }^{17,22,23}$ As a consequence, hyperventilation is considered a management option to improve systemic oxygen saturation in patients with low pulmonary blood flow after the Norwood procedure. ${ }^{10,11}$ The failure of hyperventilation to alter systemic saturation in our study patients may have been because of the fixed resistance provided by the systemic-to-pulmonary shunt or the low baseline resistance in the pulmonary vascular bed distal to the shunt. Alternatively, any reduction in pulmonary resistance effected by hyperventilation may have been offset by the accompanying increase in mean airway pressure (Table 1).

The lack of effect of hyperventilation contrasts with the results of 2 previous studies. The first examined the effects of hyperventilation in patients after a bidirectional superior cavopulmonary connection. ${ }^{24}$ In that study, hyperventilation produced a significant increase in the arteriovenous oxygen saturation difference across the upper body. This seemed to be caused by a decrease in cerebral blood flow, as indicated by transcranial Doppler sonography. ${ }^{24}$ In the current study, cerebral blood flow was not examined, but 
hyperventilation did not produce a change in arteriovenous saturation difference. It is possible that differences in patient age, cerebral venous pressure, or source of pulmonary blood flow account for the differing response to hyperventilation in these 2 studies. The second previous study examined the effects of inspired $\mathrm{CO}_{2}$ in infants after the Norwood procedure. ${ }^{20}$ In that study, respiratory acidosis, produced by adding $3 \% \mathrm{Co}_{2}$ to the inspired gas mixture, produced an increase in mixed venous saturation and a decrease in arteriovenous oxygen saturation difference. ${ }^{20}$ In the current study, respiratory alkalosis, produced by hyperventilation, produced no changes in oxygen saturations. These contrasting results may be explained by the increase in mean airway pressure during hyperventilation. After the Norwood procedure, inspired $\mathrm{Co}_{2}$ may be a more effective means of manipulating oxygen delivery than hyperventilation.

The results of this study indicate that efforts to minimize $\mathrm{FIO}_{2}$ and carefully control ventilation in the patient after the Norwood procedure may not be warranted. This is consistent with a previous report showing that hemodynamic stability and good clinical outcome can result despite a relatively high $\mathrm{FIO}_{2}$ and alkalosis in the early postoperative period. ${ }^{25}$ Increasing $\mathrm{FIO}_{2}$ from the low levels frequently used in clinical practice may be a useful approach to improve oxygen delivery. This study, as well as others, demonstrated that mixed venous oxygen saturation has a nadir 6 to 12 hours after the Norwood operation. ${ }^{1,26}$ Patients with mixed venous saturation less than $30 \%$ are at risk for anaerobic metabolism. ${ }^{27}$ Such patients might derive clinical benefit from even a relatively modest increase in oxygen delivery. In our current management strategy, the effect of $\mathrm{FIO}_{2}$ on mixed venous saturation is used to determine the optimal $\mathrm{FIO}_{2}$ in a given patient.

This study has several limitations. A small number of patients were studied in the early postoperative period under conditions of sedation and paralysis. The potential advantages or disadvantages of the study interventions under other conditions would be speculative. Each intervention was applied for a short period of time, and only 1 level of high $\mathrm{FIO}_{2}$ was studied to limit the total time of the study. All mixed venous blood samples were drawn from the superior vena cava, which may not reflect true mixed venous saturation. Finally, pulmonary and systemic blood flows, and pulmonary vascular resistance were not directly measured, because this is not generally possible in newborns after the Norwood procedure.

\section{Conclusion}

This study found that high $\mathrm{FIO}_{2}$ can improve mixed venous oxygen saturation and systemic oxygen delivery in neonates after the Norwood procedure. In contrast, hyperventilation does not change either mixed venous saturation or oxygen delivery. Under the conditions studied, neither intervention seemed to increase pulmonary blood flow at the expense of decreased systemic blood flow, blood pressure, and oxygen delivery. Increasing $\mathrm{FIO}_{2}$ may be a useful intervention in some patients with low systemic oxygen delivery after operation. These findings support the ongoing investigation of methods to maximize oxygen delivery to further improve the outcome of the Norwood procedure.

\section{References}

1. Rossi AF, Sommer RJ, Lotvin A, Gross RP, Steinberg LG, Kipel G, et al. Usefulness of intermittent monitoring of mixed venous oxygen saturation after stage 1 palliation for hypoplastic left heart syndrome. Am J Cardiol. 1994;73:1118-23.

2. Ishino K, Stumper O, De Giovanni JJV, Silove ED, Wright JGC, Sethia B, et al. The modified Norwood procedure for hypoplastic left heart syndrome: early to intermediate results of 120 patients with particular reference to aortic arch repair. J Thorac Cardiovasc Surg. 1999;117:920-30.

3. Daebritz SH, Nollert GDA, Zurakowski D, Khalil PN, Lang P, del Nido PJ, et al. Results of Norwood stage 1 operation: comparison of hypoplastic left heart syndrome with other malformations. J Thorac Cardiovasc Surg. 2000;119:358-67.

4. Barnea O, Austin EH, Richman B, Santamore WP. Balancing the circulation: theoretic optimization of pulmonary/systemic flow ratio in hypoplastic left heart syndrome. J Am Coll Cardiol. 1994;24:1376-81.

5. Barnea O, Santamore WP, Rossi A, Salloum E, Chien S, Austin EH. Estimation of oxygen delivery in newborns with a univentricular circulation. Circulation. 1998;98:1407-13.

6. Migliavacca F, Pennati G, Dubini G, Fumero R, Pietrabissa R, Urcelay G, et al. Modeling of the Norwood circulation: effects of shunt size, vascular resistances, and heart rate. Am J Physiol Heart Circ Physiol. 2001;280:H2076-86.

7. Castaneda AR, Jonas RA, Mayer JE, Hanley FL. Cardiac surgery of the neonate and infant. Perioperative care; hyperplastic left heart syndrome. Philadelphia: W.B. Saunders; 1994. pp. 81, 374.

8. Wessel DL. Commentary: simple gases and complex single ventricles. J Thorac Cardiovasc Surg. 1996;112:655-7.

9. Backer CL, Bove EL, Zales VR, Mavroudis C. Hypoplastic left heart syndrome. In: Mavroudis C, Backer CL, editors. Pediatric cardiac surgery. 2nd ed. St. Louis: Mosby; 1994. p. 447.

10. Kirklin JW, Barratt-Boyes BG. Postoperative care. In: Cardiac surgery. 2nd ed. New York: Churchill Livingstone; 1993. p. 229.

11. Austin EH. Postoperative management after the Norwood procedure. Semin Thorac Cardiovasc Surg Pediatr Card Surg Anпи. 1998;1:10921.

12. Poirier NC, Drummond-Webb JJ, Hisamochi K, Imamura M, Harrison AM, Mee RBB. Modified Norwood procedure with a high-flow cardiopulmonary bypass strategy results in low mortality without late arch obstruction. J Thorac Cardiovasc Surg. 2000;120:875-84.

13. Buheitel G, Scharf J, Hofbeck M, Singer H. Estimation of cardiac index by means of the arterial and the mixed venous oxygen content and pulmonary oxygen uptake determination in the early post-operative period after surgery of congenital heart disease. Intensive Care Med. 1994;20:500-3.

14. Charpie JR, DeKeon MK, Goldberg CS, Mosca RS, Bove EL, Kulik TJ. Postoperative hemodynamics after Norwood palliation for hypoplastic left heart syndrome. Am J Cardiol. 2001;87:198-202.

15. Tabbutt S, Ramamoorthy C, Montenegro LM, Durning SM, Kurth CD, Steven JM, et al. Impact of inspired gas mixtures on preoperative infants with hypoplastic left heart syndrome during controlled ventilation. Circulation. 2001;104(suppl I):I159-64.

16. Tweddell JS, Hoffman GM, Mussatto KA, Fedderly RT, Berger S, Jaquiss RDB, et al. Improved survival of patients undergoing palliation of hypoplastic left heart syndrome: lessons learned from 115 consecutive patients. Circulation. 2002;106(suppl I):I82-9.

17. Chang AC, Zucker HA, Hickey PR, Wessel DL. Pulmonary vascular resistance in infants after cardiac surgery: role of carbon dioxide and hydrogen ion. Crit Care Med. 1995;23:568-74. 
18. Riordan CJ, Randsbaek F, Storey JH, Montgomery WD, Santamore WP, Austin EH III. Effects of oxygen, positive end-expiratory pressure, and carbon dioxide on oxygen delivery in an animal model of the univentricular heart. J Thorac Cardiovasc Surg. 1996;112:644-54.

19. Reddy VM, Liddicoat JR, Fineman JR, McElhinney DB, Klein JR, Hanley FL. Fetal model of single ventricle physiology: hemodynamic effects of oxygen, nitric oxide, carbon dioxide, and hypoxia in the early postnatal period. J Thorac Cardiovasc Surg. 1996;112:437-49.

20. Bradley SM, Simsic JM, Atz AM. Hemodynamic effects of inspired carbon dioxide after the Norwood procedure. Ann Thorac Surg. 2001; 72:2088-94.

21. Taeed R, Schwartz SM, Pearl JM, Raake JL, Beekman RH, Manning $\mathrm{PB}$, et al. Unrecognized pulmonary venous desaturation early after Norwood palliation confounds Qp: Qs assessment and compromises oxygen delivery. Circulation. 2001;103:2699-704.

22. Morray JP, Lynn AM, Mansfield PB. Effect of $\mathrm{pH}$ and $\mathrm{pCO} 2$ on pulmonary and systemic hemodynamics after surgery in children with congenital heart disease and pulmonary hypertension. J Pediatr. 1988; 113:474-9.

23. Fullerton DA, Kirson LE, St Cyr JA, Kinnard T, Whitman GJR. Influence of hydrogen ion concentration versus carbon dioxide tension on pulmonary vascular resistance after cardiac operation. $J$ Thorac Cardiovasc Surg. 1993;106:528-36.

24. Bradley SM, Simsic JM, Mulvihill DM. Hyperventilation impairs oxygenation after bidirectional superior cavopulmonary connection. Circulation. 1998;98(suppl II):II372-7.

25. Mosca RS, Bove EL, Crowley DC, Sandhu SK, Schork MA, Kulik TJ. Hemodynamic characteristics of neonates following first stage palliation for hypoplastic left heart syndrome. Circulation. 1995;92(suppl II):II267-71 .

26. Tweddell JS, Hoffman GM, Fedderly RT, Berger S, Thomas JP, Ghanayem NS, et al. Phenoxybenzamine improves systemic oxygen delivery after the Norwood procedure. Ann Thorac Surg. 1999;67: 161-8.

27. Hoffman GM, Ghanayem NS, Kampine JM, Berger S, Mussatto KA, Litwin SB, et al. Venous saturation and the anaerobic threshold in neonates after the Norwood procedure for hypoplastic left heart syndrome. Ann Thorac Surg. 2000;70:1515-21.

\section{Discussion}

Dr James S. Tweddell (Milwaukee, Wis). Dr Bradley, I congratulate you on an outstanding presentation that adds to our understanding of the management of patients after stage 1 palliation of hypoplastic left heart syndrome.

This type of systematic analysis of postoperative management strategies is critical if we are to improve outcomes both in terms of early mortality and long-term morbidity, particularly in neurodevelopmental outcome.

Francis and colleagues from the Royal Brompton Hospital stated it well when they said that for any given arterial oxygen content, an increase in systemic output would be clearly beneficial.

I think the corollary of that statement, that for any given systemic output, an increase in arterial oxygen content would clearly be beneficial, is equally correct. This much is not in contention.

You have demonstrated that, at least acutely, the use of a higher $\mathrm{FIO}_{2}$ results in improved systemic oxygen delivery. Your findings also indicate that at least in the acute setting, increasing arterial saturation correlates positively with increasing systemic venous saturation.

Therefore, an elevated arterial saturation in the postoperative hypoplast is not a harbinger of impending doom, but may reflect excellent cardiac output and systemic oxygen delivery.
Indeed, the management strategy unique to this set of patients, which is actually to increase their level of cyanosis, is one still commonly used and with little objective data to justify it.

This study demonstrates practically and irrefutably the benefits and even the necessity of objective assessment of systemic oxygen delivery using continuous venous saturation monitoring.

Using our current management strategies, we also noted a positive correlation between arterial and venous saturation in the same group of patients. This slide reflects approximately 2500 patient hours of data and correlates the arterial saturation and venous saturation of those patients receiving the current management strategy using phenoxybenzamine. I think you can see clearly a very strong positive correlation between arterial and venous saturation over a wide range.

As a consequence, our management strategy does not call for tight control of arterial saturation using ventilatory manipulations or medical gas management. We commonly use an $\mathrm{FIO}_{2}$ of $40 \%$. Instead, we target the venous saturation, as you have done, as an indicator of a satisfactory postoperative course.

How have these findings changed your postoperative management? For this study, you did indeed target an arterial saturation of $80 \%$. Have you abandoned a strategy of limiting arterial saturation during the postoperative period?

During the postgraduate course, you showed us some very interesting data regarding your experience with the Sano modification of stage 1 palliation. It has been suggested that this modification diminishes the need for complex ventilator management.

On the basis of your experience with the RV-PA conduit, can you provide us with any objective data to support those claims?

Interestingly, you did not identify an impact of hyperventilation on systemic oxygen delivery, yet your previous studies indicate that the addition of $\mathrm{CO}_{2}$ to the inspired gas mixture of patients after the Norwood procedure did in fact result in a reduction of the Qp:Qs. I wonder whether you have considered repeating this portion of the study controlling for mean airway pressure to see whether hypocapnia does indeed result in elevation of pulmonary to systemic flow ratio.

Dr Bradley. Thank you for your comments. Certainly many of them reinforce our results. It is particularly interesting that you observed a positive correlation between systemic and mixed venous saturations in your patients receiving phenoxybenzamine and that we observed the same in patients not receiving phenoxybenzamine.

We began monitoring mixed venous saturation in late 1996. Since that time, our postoperative management has not been aimed at targeting a particular arterial saturation or limiting arterial saturation, rather it has been aimed at optimizing mixed venous saturation. For the baseline in this study, we selected an arterial saturation of $75 \%$ to $80 \%$, but that is not generally the approach of our postoperative management.

In terms of the Sano modification, the information I showed yesterday was quite preliminary, being based on only 10 patients. It showed that the mixed venous saturations in the patients with an RV-to-PA shunt were very similar to those in the patients with a modified Blalock-Taussig shunt during the first 24 hours. At this point, I really do not know whether ventilatory manipulations will be any more or less important with the Sano modification than with the modified Blalock-Taussig shunt. 
We were also interested in the lack of effect produced by hyperventilation, given our previous results with inspired carbon dioxide. I would be cautious in making conclusions about Qp/Qs. $\mathrm{Qp} / \mathrm{Qs}$ calculations, as everyone is aware, depend on the level of pulmonary venous saturation. Although we may frequently assume these are normal in patients after the Norwood procedure, an important study from the Cincinnati group showed that even in the presence of a clear chest x-ray film (in the 1- to 3-day postoperative period), pulmonary venous saturations are often decreased and that these decreases can result in fairly large errors in calculated Qp/Qs. So we have avoided assumed calculations of Qp:Qs. What we did show in our previous study was that inspired carbon dioxide increased mixed venous saturation, which was directly measured. A decrease in Qp/Qs may have been one explanation. Another may have been that $\mathrm{CO}_{2}$ is a systemic vasodilator, and you have been a leader in teaching us that systemic vasodilation may be useful after the Norwood procedure. As you suggest, the increase in mean airway pressure during hyperventilation may have negated any effects of hypocapnia, which would be interesting to look at in the future.

Dr Peter B. Manning (Cincinnati, Ohio). Scott, because we looked at a very similar population and collected a very similar data set, and the one additional piece of information we measured was the pulmonary venous saturations, I can confirm your speculation that pulmonary venous desaturation may in fact be playing a part. In $30 \%$ of the samples in our study, there was pulmonary venous desaturation, and our study was a little different in that we varied the $\mathrm{FIO}_{2}$ from $17 \%$ to as high as $50 \%$.
Even when the $\mathrm{FIO}_{2}$ was $30 \%$, which was the level you were ventilating the kids with, we still saw some individual data points in which there was pulmonary venous desaturation.

We could always correct that by pushing the $\mathrm{FIO}_{2}$ up to $50 \%$. I would be interested, although you presented the data at just $100 \%$, if you had other data as far as when you get that correction below $100 \%$, as we saw.

The other thing we noticed was that if we pushed the peak end-expiratory pressure up quite often, we could get rid of the pulmonary venous desaturation without necessarily changing the $\mathrm{FIO}_{2}$. We may be correcting some V/Q mismatch, and I was curious what tidal volumes and levels of peak end-expiratory pressure you used.

I thought it was an excellent study.

Dr Bradley. Thank you, Peter. I do appreciate your study. I think it was very important in showing us that pulmonary venous desaturation can be very common and that our Qp/Qs calculations may not be accurate.

We did not do any oxygen titration, as you did, so I can't comment on the optimal level of oxygen. We picked 1 level of $\mathrm{FIO}_{2}$ for this study to limit the time period. In clinical management, I think it would be useful to titrate the oxygen, follow the mixed venous saturation, and pick the optimal $\mathrm{FIO}_{2}$ on that basis.

In general, our patients were ventilated with peak end-expiratory pressure $=3 \mathrm{~cm}$ of water, tidal volumes of approximately 20 $\mathrm{mL} / \mathrm{kg}$, and peak airway pressures that ended up being in the low 20s. None of these were altered during this study. 